\title{
Simulation Evaluation Model of Airport Airspace and Ground Operational Efficiency
}

\author{
Xiong $\mathrm{Li}^{1,{ }^{*}}$, Xiaoqing Chen ${ }^{2}$ and Dongbin $\mathrm{Li}^{3}$ \\ ${ }^{1}$ Planning and Design Institute, China Airport Construction Group Corporation, Beijing, China \\ ${ }^{2}$ Aviation Industry Development Research Center of China, Beijing, China \\ ${ }^{3}$ Department of Air Traffic Management, Civil Aviation of Management Institute of China, Beijing, China \\ ${ }^{*}$ Corresponding author
}

\begin{abstract}
It has great significance for airport planning and design to build simulation model and evaluate scientifically for airport airspace and ground operation. The evaluation model of airport airspace and ground operation was constructed by using analytic hierarchy process (AHP). 5 airspace operation indexes were selected respectively: potential impact to military aviation, airspace demand range, number of arriving and departure routes, flow equilibrium of entry and exit point, arrival air delays time. 7 evaluation indexes of ground operation were selected: number of daily departure and arrival flights, equilibrium of runway usage, departure ground delays time, ground taxiing time, usage equilibrium of main taxiway, turnover frequency of contact gate, air bridge ratio. Then, the calculation methods of various indexes were given. Finally, index scale method was used to determine the weight of each index, which had better ordering, consistency and uniformity.
\end{abstract}

Keywords-airport; analytic hierarchy process; simulation; airspace; operational efficiency

\section{INTRODUCTION}

The continuous growth of social economy drives China air transport on the fast-growing track, during which China civil aviation has become the second largest air transport system in the world. The growth of aviation demand results in huge pressure on the operation of large hub airports in China. The simulation technology is often used through the process of evaluating the status of the airport or the renovation plan to enhance its operational efficiency, so as to build up the computer model for terminal airspace and airfield ground[1-3]. By analyzing the simulation results, lots of operating data can be obtained.

However, in order to make an effectively comprehensive comparison and selection, it is necessary to select the appropriate evaluation index, determine the weighting factor of each index and give the comprehensive selection results with indexes of the alternatives. But there is still a lack of reference to this research at present. In this occasion, this paper put up with the calculation method of each index and determined the corresponding weight value by building comprehensive evaluation analytic hierarchy model of the airspace and ground based on the analytic hierarchy process (AHP) of operational research [4].

\section{EVALUATION INDEX}

It is necessary to evaluate the operational efficiency of an airfield planning scheme from both airspace and ground in terms of flight operation. As for airspace operation, the planning stage mainly includes the terminal airspace occupation area in airport, coordination between civil aviation and military, departure routes diversion, and the air delays time, etc. As for ground operation, the main considerations are the runway efficiency, taxiing smoothness, flight efficiency and ground delays time, etc. Based on the analysis above and the stimulation results, an analytic hierarchy model is constructed. It can be seen from Figure 1 that it is divided into four hierarchies: target layer, criterion layer, index layer and scheme layer.

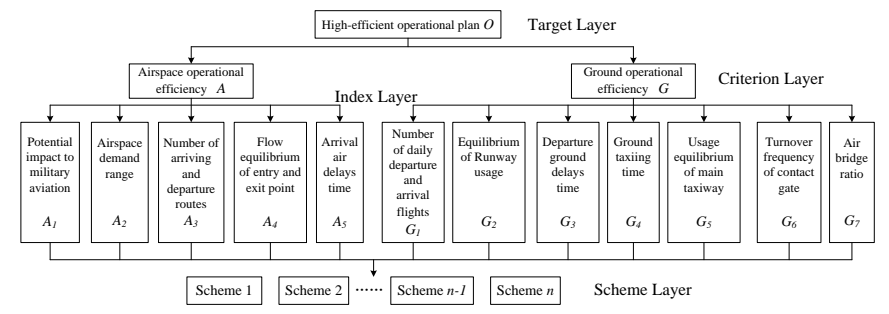

FIGURE I. HIERARCHY STRUCTURE OF EVALUATION OF OPERATIONAL EFFICIENCY

\section{EVALUATION INDEX CALCULATION}

\section{A. Evaluation Index in Airspace Operation}

\section{1) Potential impact to military aviation}

Based on the routes, training airspace and special airspace of the military aviation around the target civil airports, this paper divided the routes and airspace into several airspace units according to certain rules. The size of the airspace units depends on the analytical airspace range and the number of units in large airport usually ranges from 100 to 200. Assuming that there are $n$ airspace schemes of departure routes in the target airport, then the number of military aviation units affected in each scheme is $A_{1}^{Y X}(i), \quad i=1, \cdots, n$. The calculation equation of the potential impact index to military aviation $A_{1}(i)$ is: 


$$
A_{1}(i)=\min A_{1}^{Y X} / A_{1}^{Y X}(i)
$$

The $\min A_{1}^{Y X}=\min \left\{A_{1}^{Y X}(1), A_{1}^{Y X}(2), \cdots, A_{1}^{Y X}(n)\right\}$ in equation (1) refers to the minimum value of affected military aviation units in each scheme. The greater the value of $A_{1}(i)$ is, the smaller the potential impact to military aviation is.

\section{2) Airspace demand range}

Calculate the airspace required in each scheme $A_{2}^{K F}(i)$, $i=1, \cdots, n$ according to the use of airspace by airport and the width of the departure route. The calculation equation of airspace demand range $A_{2}(i)$ is:

$$
A_{2}(i)=\min A_{2}^{K F} / A_{2}^{K F}(i)
$$

The $\min A_{2}^{K F}=\min \left\{A_{2}^{K F}(1), A_{2}^{K F}(2), \cdots, A_{2}^{K F}(n)\right\} \quad$ in this equation refers to the minimum value of airspace demand range in each scheme. The smaller the value of $A_{2}(i)$ is, the greater the airspace demand range is.

\section{3) Number of arriving and departure routes}

Taking the operating conditions of airport main landing and sub-landing into consideration, the number of arriving and departure routes in each scheme is $A_{3}^{H S}(i), i=1, \cdots, n$. The calculation equation of the number of arriving and departure routes is:

$$
A_{3}(i)=A_{3}^{H S}(i) / \max A_{3}^{H S}
$$

The $\max A_{3}^{H S}=\max \left\{A_{3}^{H S}(1), A_{3}^{H S}(2), \cdots, A_{3}^{H S}(n)\right\}$ in equation (3) refers to the maximum value of arriving and departure routes. The greater the value of $A_{3}(i)$ is, the greater the number of routes is, which is conducive to the diversion of departure and landing flights.

\section{4) Flow equilibrium of entry and exit point}

Assuming that there are $n_{i}^{P}$ entry and exit points in Scheme $i$, the flight flow rate of each entry and exit point is $S^{P}(i, j)$, $i=1, \cdots, n, j=1, \cdots, n_{i}^{P}$. The standard deviation $A_{4}^{P S}(i)$ of the flight flow rate of the entry and exit points in Scheme $i$ is:

$$
A_{4}^{P S}(i)=\sqrt{\frac{\sum_{j=1}^{n_{i}^{P}}\left[S^{P}(i, j)-S^{P}(i)\right]^{2}}{n_{i}^{P}-1}}
$$

The $S^{P}(i)$ in the equation refers to the mean value of flow ratio of entry and exit points in Scheme i. The calculation equation of the traffic equilibrium index of flight flow rate of entry and exit point $A_{4}(i)$ is:

$$
A_{4}(i)=\min A_{4}^{P S} / A_{4}^{P S}(i)
$$

The $\min A_{4}^{P S}=\min \left\{A_{4}^{P S}(1), A_{4}^{P S}(2), \cdots, A_{4}^{P S}(n)\right\}$ in equation (5) refers to the minimum value of standard deviation of flight flow rate of entry and exit points in various schemes. The greater the value of $A_{4}(i)$ is, the greater the flow equilibrium of entry and exit point is.

\section{5) Arrival air delays time}

The average air delays time for arriving flights in various schemes is $A_{5}^{A D}(i), i=1, \cdots, n$. The calculation equation of arrival air delays time index $A_{5}(i)$ is:

$$
A_{5}(i)=\min A_{5}^{A D} / A_{5}^{A D}(i)
$$

The $\min A_{5}^{A D}=\min \left\{A_{5}^{A D}(1), A_{5}^{A D}(2), \cdots, A_{5}^{A D}(n)\right\}$ in above equation refers to the minimum value of average arrival air delays time in various schemes. The greater the value of $A_{5}(i)$ is, the less time the arrival air delays is.

\section{B. Evaluation Index in Ground Operation}

\section{1) Number of daily departure and arrival flights}

The number of daily departure and arrival (D/A) flights in various schemes can be marked as $G_{1}^{F M}(i), i=1, \cdots, n$. The calculation formula of number of daily D/A flights $G_{1}(i)$ is:

$$
G_{1}(i)=G_{1}^{F M}(i) / \max G_{1}^{F M}
$$

The $\max G_{1}^{F M}=\max \left\{G_{1}^{F M}(1), G_{1}^{F M}(2), \cdots, G_{1}^{F M}(n)\right\}$ in above equation refers to the maximum value of the number of daily D/A flights in various schemes. The greater the value of $G_{1}(i)$ is, the greater the airport daily capacity is.

\section{2) Equilibrium of runway usage}

There are usually multiple runways in large airports, and the usage of those runways varies. Assuming that Scheme i planned $n_{i}^{R}$ runways with the D/A flights rate of each runway accounted for $S^{R}(i, k), i=1, \cdots, n, k=1, \cdots, n_{i}^{R}$. The standard deviation $G_{2}^{R S}(i)$ of the D/A flights rate in Scheme $i$ is:

$$
G_{2}^{R S}(i)=\sqrt{\frac{\sum_{k=1}^{n_{i}^{R}}\left[S^{R}(i, k)-S^{R}(i)\right]^{2}}{n_{i}^{R}-1}}
$$


The $S^{R}(i)$ in this formula refers to the mean value of the $\mathrm{D} / \mathrm{A}$ flights rate of each runway in Scheme $i$. The calculation formula of equilibrium index $G_{2}(i)$ of runway usage is:

$$
G_{2}(i)=\min G_{2}^{R S} / G_{2}^{R S}(i)
$$

The $\min G_{2}^{R S}=\min \left\{G_{2}^{R S}(1), G_{2}^{R S}(2), \cdots, G_{2}^{R S}(n)\right\}$ in this formula refers to the minimum value of the standard deviation of the $\mathrm{D} / \mathrm{A}$ flights rate in various schemes. The greater the value of $G_{2}(i)$ is, the stronger the equilibrium of runway usage is.

\section{3) Departure ground delays time}

The average ground delays time for departure flights in various schemes is $G_{3}^{G D}(i), i=1, \cdots, n$. The calculation equation of departure ground delays time $G_{3}(i)$ is:

$$
G_{3}(i)=\min G_{3}^{G D} / G_{3}^{G D}(i)
$$

The $\min G_{3}^{G D}=\min \left\{G_{3}^{G D}(1), G_{3}^{G D}(2), \cdots, G_{3}^{G D}(n)\right\} \quad$ in this equation refers to the minimum value of average ground delays time for departure flights in various schemes. The greater the value of $G_{3}(i)$ is, the less time the departure ground delays is.

\section{4) Ground taxiing time}

The average ground taxiing time in various schemes is $G_{4}^{T S}(i), i=1, \cdots, n$. Taking the average taxiing time of both departure and arrival flights into consideration, the calculation equation of the ground taxiing time $G_{4}(i)$ is:

$$
G_{4}(i)=\min G_{4}^{T S} / G_{4}^{T S}(i)
$$

The $\min G_{4}^{T S}=\min \left\{G_{4}^{T S}(1), G_{4}^{T S}(2), \cdots, G_{4}^{T S}(n)\right\}$ in equation (11) refers to the minimum value of the average ground taxiing time in various schemes. The greater the value of $G_{4}(i)$ is, the less time the average taxiing spends.

\section{5) Usage equilibrium of main taxiway}

Assuming that Scheme $\mathrm{i}$ mainly focused on $n_{i}^{T}$ main taxiways with the usage frequency of each main taxiways as $S^{T}(i, l), i=1, \cdots, n, l=1, \cdots, n_{i}^{T}$. The standard deviation $G_{5}^{T S}(i)$ of usage frequency of main taxiways in Scheme $i$ is:

$$
G_{5}^{T S}(i)=\sqrt{\frac{\sum_{l=1}^{n_{i}^{T}}\left[S^{T}(i, l)-S^{T}(i)\right]^{2}}{n_{i}^{T}-1}}
$$

The $S^{T}(i)$ in the equation refers to the mean value of the usage frequency of each main taxiways in Scheme $i$. The calculation equation of usage equilibrium index $G_{5}(i)$ of main taxiway is:

$$
G_{5}(i)=\min G_{5}^{T S} / G_{5}^{T S}(i)
$$

The $\min G_{5}^{T S}=\min \left\{G_{5}^{T S}(1), G_{5}^{T S}(2), \cdots, G_{5}^{T S}(n)\right\}$ in equation (13) refers to the minimum value of the standard deviation of usage frequency of main taxiways in various schemes. The greater the value of $G_{5}(i)$ is, the stronger the usage equilibrium of main taxiway is.

\section{6) Turnover frequency of contact gate}

Each time an aircraft slide in or out the gates will be counted as a gate turnover. Assuming that the turnover frequency of international and domestic contact gate is $N^{I G}(i)$ and $N^{D G}(i)$ respectively in Scheme $i$, the assessment membership function of international and domestic flight turnover frequency can be shown in equation (14) and (15).

$$
\begin{gathered}
G_{6}^{I G}(i)=\left\{\begin{array}{cc}
1 & N^{I G}(i) \geq 8 \\
0.75 & 6 \leq N^{I G}(i)<8 \\
0.5 & 4 \leq N^{I G}(i)<6 \\
0.25 & N^{I G}(i)<4
\end{array}\right. \\
G_{6}^{D G}(i)=\left\{\begin{array}{cc}
1 & N^{D G}(i) \geq 12 \\
0.75 & 9 \leq N^{D G}(i)<12 \\
0.5 & 6 \leq N^{D G}(i)<9 \\
0.25 & N^{D G}(i)<6
\end{array}\right.
\end{gathered}
$$

The calculation equation of turnover frequency of contact gate $G_{6}(i)$ is:

$$
G_{6}(i)=0.5 G^{I G}(i)+0.5 G^{D G}(i)
$$

\section{7) Air bridge ratio}

Air bridge ratio refers to the percentage of daily flights that are docked in a near aircraft seat on a daily run. Assuming that the air bridge ratio of international flights and domestic flights is $R^{I R}(i)$ and $R^{D R}(i)$ respectively in Scheme $\mathrm{i}$, the assessment membership function of international and domestic flight air bridge ratio can be shown in equation (17) and (18). 


$$
\begin{gathered}
G_{7}^{I R}(i)=\left\{\begin{array}{cc}
1 & R^{I R}(i) \geq 95 \% \\
0.8 & 90 \% \leq R^{I R}(i)<95 \% \\
0.6 & 85 \% \leq R^{I R}(i)<90 \% \\
G^{I R}(i) / 2 & R^{I R}(i)<85 \%
\end{array}\right. \\
G_{7}^{D R}(i)=\left\{\begin{array}{cc}
1 & R^{D R}(i) \geq 90 \% \\
0.8 & 80 \% \leq R^{D R}(i)<90 \% \\
0.6 & 70 \% \leq R^{D R}(i)<80 \% \\
G^{D R}(i) / 2 & R^{D R}(i)<70 \%
\end{array}\right.
\end{gathered}
$$

The calculation equation of air bridge ratio $G_{7}(i)$ is:

$$
G_{7}(i)=0.5 G^{I R}(i)+0.5 G^{D R}(i)
$$

\section{DEtermination OF IndEX Weight}

With the application of analytic hierarchy process, this paper made a paired-comparison of indicators in different levels, obtained the judgment matrix, calculated the weighting factors of various indexes and conducted the consistency test. The basic thought and calculation of the analytic hierarchy process can be referred from $[4,5]$ and will not be elaborated in this paper.

In the analytic hierarchy model of airspace and ground operational efficiency evaluation, the hierarchies involved airspace operation and ground operation. In terms of the flight operation in airport terminal, both the airspace and ground operation are of great importance. Thus, the airspace operational efficiency weights will be set as $w^{A}=0.5$, and the ground operational efficiency weights as $w^{G}=0.5$.

The index scale method serves as the reference to the importance of two indexes in the paired-comparison in judgment matrix. This method is better in order-preserving, consistency and uniformity compared with the traditional 1-9 scale method [6]. The difference of two methods can be shown in Table 1.

TABLE I. DIFFERENCE OF TWO SCALE METHODS

\begin{tabular}{|c|c|c|}
\hline Difference Description & 1-9 Scale Method & Index Scale Method \\
\hline Same important & 1 & $e^{0 / 4}(1)$ \\
\hline Tiny important & 2 & $e^{1 / 4}(1.284)$ \\
\hline Slight important & 3 & $e^{2 / 4}(1.649)$ \\
\hline Important & 4 & $e^{3 / 4}(2.117)$ \\
\hline Obviously important & 5 & $e^{4 / 4}(2.718)$ \\
\hline Quite important & 6 & $e^{5 / 4}(3.490)$ \\
\hline Very important & 7 & $e^{6 / 4}(4.482)$ \\
\hline Great important & 8 & $e^{7 / 4}(5.755)$ \\
\hline Extreme important & 9 & $e^{8 / 4}(7.390)$ \\
\hline
\end{tabular}

\section{A. Index Weight of Airspace Operational Efficiency}

With comprehensive consideration including the airspace plan in airport terminal, approaching traffic control, opinions of flight personnel and experts of airport planning and design, this paper made paired-comparison of 5 airspace operational efficiency indexes consisting of potential impact to military aviation $A_{1}$, airspace demand range $A_{2}$, the number of arriving and departure routes $A_{3}$, flow equilibrium of entry and exit point $A_{4}$ and the arrival air delays time $A_{5}$. The obtained judgment matrix is shown in Table 2.

Calculate the weight value of airspace operational efficiency indexes $A_{1} \sim A_{5}$ by sum algorithm. The weight value is $w_{1}^{A}=0.141, w_{2}^{A}=0.072, w_{3}^{A}=0.268, w_{4}^{A}=0.078, w_{5}^{A}=0.441$ respectively. Conduct the consistency check. $\lambda_{\max }=5.069$, $C I=0.017, R I=1.12$, and $C R=0.015<0.1$ is obtained, which meet the consistency requirement.

TABLE II. JUDGMENT MATRIX OF AIRSPACE INDEXES

\begin{tabular}{|c|c|c|c|c|c|}
\hline$A$ & $A_{1}$ & $A_{2}$ & $A_{3}$ & $A_{4}$ & $A_{5}$ \\
\hline$A_{1}$ & 1 & 2.718 & 0.472 & 1.649 & 0.287 \\
\hline$A_{2}$ & 0.368 & 1 & 0.223 & 1.284 & 0.174 \\
\hline$A_{3}$ & 2.117 & 4.482 & 1 & 2.718 & 0.606 \\
\hline$A_{4}$ & 0.606 & 0.779 & 0.368 & 1 & 0.174 \\
\hline$A_{5}$ & 3.490 & 5.755 & 1.649 & 5.755 & 1 \\
\hline
\end{tabular}

\section{B. Index Weight of Ground Operational Efficiency}

With comprehensive consideration including the ground management in airport terminal, air tower traffic control, opinions of flight personnel and experts of airport planning and design, this paper made paired-comparison of 7 ground operational efficiency indexes including number of daily departure and arrival flights $G_{1}$, equilibrium of runway usage $G_{2}$, departure ground delays time $G_{3}$, ground taxiing time $G_{4}$, usage equilibrium of main taxiway $G_{5}$, turnover frequency of contact gate $G_{6}$ and air bridge ratio $G_{7}$. The obtained judgment matrix is shown in Table 3.

TABLE III. JUDGMENT MATRIX OF GROUND INDEXES

\begin{tabular}{|c|c|c|c|c|c|c|c|}
\hline$G$ & $G_{1}$ & $G_{2}$ & $G_{3}$ & $G_{4}$ & $G_{5}$ & $G_{6}$ & $G_{7}$ \\
\hline$G_{1}$ & 1 & 2.718 & 0.606 & 2.117 & 2.718 & 3.490 & 2.718 \\
\hline$G_{2}$ & 0.368 & 1 & 0.472 & 0.606 & 2.117 & 1.649 & 1.284 \\
\hline$G_{3}$ & 1.649 & 2.117 & 1 & 2.718 & 3.490 & 4.482 & 3.490 \\
\hline$G_{4}$ & 0.472 & 1.649 & 0.368 & 1 & 1.649 & 2.117 & 1.649 \\
\hline$G_{5}$ & 0.368 & 0.472 & 0.287 & 0.606 & 1 & 1.284 & 0.779 \\
\hline$G_{6}$ & 0.287 & 0.606 & 0.223 & 0.472 & 0.779 & 1 & 0.606 \\
\hline$G_{7}$ & 0.368 & 0.779 & 0.287 & 0.606 & 1.284 & 1.649 & 1 \\
\hline
\end{tabular}

Calculate the weight value of ground operational efficiency indexes $G_{1} \sim G_{7}$ by sum algorithm. The weight value is 
$w_{1}^{G}=0.232, w_{2}^{G}=0.113, w_{3}^{G}=0.299, w_{4}^{G}=0.132, w_{5}^{G}=0.074$, $w_{6}^{G}=0.062, w_{7}^{G}=0.088$ respectively. Conduct the consistency check. $\lambda_{\max }=7.085, C I=0.014, R I=1.32$, and $C R=0.013<0.1$ is obtained, which meet the consistency requirement.

\section{Weight Based on Total Objective}

The weight of each index multiplying the corresponding membership criterion weights equals the weight value of the index relative to the total target. The weight values of the evaluation index of airspace and ground operational efficiency relative to the high-efficient operational plan are 0.070, 0.036, 0.134, 0.039 and 0.221 (corresponding to $A_{1} \sim A_{5}$ ); 0.116, 0.057, 0.149, 0.066, 0.037, 0.031 and 0.044 (corresponding to $\left.G_{1} \sim G_{7}\right)$. Consistency inspection index turned out to be $C R=0.013<0.1$, showing that the weight based on total objectives can meet the consistency requirement.

\section{CONCLUSIONS}

The evaluation model of airport airspace and ground operation is constructed by using analytic hierarchy process (AHP), and the conclusions are as follows: (1) In terms of the airspace operational efficiency, arrival air delays time and the number of arriving and departure routes serve as the main factors; while as for ground operational efficiency, departure ground delays time and daily number of D/A flights are accounted for the main factors. (2) The index scale method to determine the weight of each index is better in order-preserving, consistency and uniformity, and which can also meet the evaluation requirements. (3) It is a complex task to evaluate the operation efficiency of large airports. In the future, it can be deeply analyzed with specific airport simulation cases.

\section{ACKNOWLEDGMENTS}

This work is supported by two research projects: (1) China civil aviation security ability building funds (2016) --Research on application of simulation technology in civil airport planning and design; (2) National Key Technologies R\&D Program (2014BAJ04B02).

\section{REFERENCES}

[1] X. Li, D.B. Li, D.X. Wei, and X.Q. Chen, "Utilization pattern of closely spaced parallel runways and simulation of operational efficiency," International Conference on Progress in Informatics and Computing (PIC-2015), Nanjing, China, 2015, pp.158-162.

[2] H.N. Wu, Y.C. Guo, T. Mu, and X. Li, "Apron taxiway operation mode and simulation evaluation in Beijing new airport," Journal of Transportation Systems Engineering and Information Technology vol. 16, no. 3, pp 214-220, 2016.

[3] W. Gao, and C.W. Huang, "Research on capacity evaluation for Chongqing TMA," Journal of Civil Aviation Univ. of China, vol. 28, no. 5, pp 1-4, 2010.

[4] J.Y. Guo, Z.B. Zhang, and Q.Y. Sun, "Study and application of analytic hierarchy process,” China Safety Science Journal, vol. 18, no. 5, pp. 148-153, 2008.

[5] X. Li, and X.H. Xu, "Flight rerouting path evaluation method in air traffic,” Flight Dynamics, vol. 29, no. 1, pp. 84-88, 2011.
[6] Z.Q. Luo, and S.L. Yang, "Comparative study on several scales in AHP,” Systems Engineering - Theory \& Practice, vol. 24, no. 9, pp. 5160, 2004 . 